\title{
Physiological responses of the airway wall and lung in hyperresponsive pigs
}

\author{
D.J. Turner*, P.R. Gray*, S.A. Taylor*, J. Thomas*, H.W. Mitchell*
}

Physiological responses of the airway wall and lung in hyperresponsive pigs. D.J. Turner, P.R. Gray, S. A. Taylor, J. Thomas, H.W. Mitchell. C ERS Journals Ltd 2001.

ABSTRACT: Airway hyperresponsiveness (AHR) might be driven by mechanisms inherent to the airway wall, and/or by factors arising from outside the airways. A porcine model of allergen-induced AHR was utilized to investigate physiological responses in intact airways in vitro and their contribution to responsiveness in vivo.

Responsiveness to acetylcholine (ACh) was measured in eight ovalbumin (OA)sensitized/challenged pigs (tests) and eight saline-challenged controls. In vivo responsiveness to $\mathrm{ACh}$ was determined from pulmonary resistance $(R \mathrm{~L})$. In vitro responsiveness to $\mathrm{ACh}$ was determined from airway pressure in isovolumic bronchial segments, after exposure via the adventitial or the luminal surface.

Test pigs had lung $(255 \pm 26 \%$ increase in $R \mathrm{~L}, \mathrm{p}<0.0001)$ and skin responses to $\mathrm{OA}$, and AHR to ACh $(\mathrm{p}<\mathbf{0 . 0 0 0 1})$. In vitro, test bronchi were less sensitive than controls to ACh applied to the airway adventitia (negative log of the ACh concentration producing half the maximum response $(\mathrm{pD} 2)=4.18$ and 4.58 respectively, $\mathrm{p}<0.01)$, but not the lumen. Test bronchi had an increased amount of smooth muscle normalized for airway size versus controls $(\mathrm{p}<\mathbf{0 . 0 5})$. Maximum responses to lumenal $\mathrm{ACh}$ in vitro showed a weak positive correlation with maximum changes to $\mathrm{ACh}$ in vivo $(\mathrm{r}=0.599, \mathrm{p}=0.05)$.

This study concludes that the effect of antigen challenge on bronchial responsiveness varies with the route of exposure to acetylcholine. In vitro responses to lumenal acetylcholine are increased despite a possible reduction in responsiveness of airway smooth muscle. Responsiveness of the bronchial wall only partially explains responsiveness of the lungs in vivo.

Eur Respir J 2001; 18: 935-941.
*Dept of Physiology, University of Western Australia and "\# Dept of Pathology, Murdoch University, Perth, Western Australia, Australia.

Correspondence: D.J. Turner, Dept of Physiology, University of Western Australia, Nedlands, WA 6907, Australia. Fax: 61893801025

Keywords: Acetylcholine airway hyperresponsiveness allergen

bronchi

smooth muscle

Received: March 202001 Accepted after revision July 302001

This work was supported by the National Health and Medical Research Council of Australia.
Despite the central role of airway narrowing in the response of the lung to provocative stimuli, its importance in airway hyperresponsiveness (AHR) has not been established. Since smooth muscle contraction is a major determinant of airway diameter, one proposal has been that AHR is due to altered contractile behaviour of airway smooth muscle (ASM). Studies in allergic animal models indicate that ASM contraction might be increased [1-3], while the responses of smooth muscle isolated from asthmatics are variable $[4,5]$. In vivo, ASM is subject to additional factors arising from outside the airway, such as load from parenchymal tethering [6]. Some studies suggest that asthmatic bronchi have a reduced susceptibility to forces from parenchymal tethering, which could favour greater airway narrowing when the airway is stimulated [6, 7].

Many studies have focused on the responses of ASM after its isolation from the, airway, usually the trachea [8]. In contrast, physiological responses described in intact bronchial airways isolated from asthmatics or animals models are scarce and the contributions that the bronchial wall may make to AHR in vivo remains controversial. A porcine model of AHR is presented in this study, which because of its size and ready availability allows the functional properties of different size bronchi to be investigated [9, 10]. Early allergen-induced responses have previously been reported in the pig [7, 11]. The preliminary aim of this current study was, therefore, to determine whether sensitization and repeated allergen exposure in pigs subsequently led to AHR. A further aim was to establish for the first time whether or not physiological responses in intact bronchi isolated from hyperresponsive pigs were increased. It was hypothesized that if AHR in vivo is due to physiological or morphological changes to the bronchial wall, then there should be an increase in responsiveness of bronchi isolated from the lung. In vitro responses were assessed in a bronchial segment, which preserves the structural components of the wall in their normal geometric relationship. This allows the smooth muscle to be exposed to contractile stimuli directly, via the adventitial surface, or via the airway lumen to simulate in vivo aerosol challenge.

\section{Materials and methods}

\section{Sensitization procedure}

Sixteen White/Landrace female pigs $(10 \mathrm{~kg})$ were studied. Eight test animals were sensitized to ovalbumin 
(OA) on day 0 and 7 as previously described [7]. Four control animals were sham sensitized (saline and adjuvant) on corresponding days, while four naïve controls were housed for the same duration without receiving any injections.

\section{Cutaneous responses}

Success of sensitization was determined on day 14 and 20 using $50 \mu \mathrm{L}$ intradermal injections of $\mathrm{OA}$ in 10 -fold dilutions $\left(0.001-1 \mathrm{mg} \cdot \mathrm{mL}^{-1}\right)$. The lowest concentration of $\mathrm{OA}$ at which a positive response (red wheal $>5 \mathrm{~mm}$ diameter) occurred was recorded and used as an index of reactivity to the allergen [12].

\section{Aerosol challenge}

Test animals received OA aerosol $\left(50 \mathrm{mg} \cdot \mathrm{mL}^{-1}\right.$ in saline) on days 14, 17 and 20 while anaesthetized and intubated, as described previously [7]. Control animals received aerosols of saline alone. Pulmonary resistance $(R \mathrm{~L})$ and dynamic compliance $(C \mathrm{~L})$ were measured using an established protocol [7]. Measurements were made at baseline and for $30 \mathrm{~min}$ following challenge to detect early allergen responses.

\section{Assessment of airways hyperresponsiveness in vivo}

Airway responsiveness was determined from concentration-response curves (CRCs) to doubling concentrations of acetylcholine (ACh; Sigma Castlehill, NSW, Australia) dissolved in saline. Solutions were delivered as aerosols into the airways for $60 \mathrm{~s}$, as described for allergen delivery [7]. $R \mathrm{~L}$ and $C \mathrm{~L}$ were measured before and after each concentration. Increasing concentrations of $\mathrm{ACh}$ were administered until $R \mathrm{~L}$ reached a plateau. Baseline responsiveness was measured on day 14, prior to the first challenge, and again on day 20,1 hr after the final challenge. Reactivity to ACh was determined from the maximal $R \mathrm{~L}$ recorded during the $\mathrm{CRC}$. Sensitivity to $\mathrm{ACh}$ was determined from the concentration of $\mathrm{ACh}$ required to increase $R \mathrm{~L} 50 \%$ between baseline and the maximum $R \mathrm{~L}$ value obtained (PC50).

\section{Assessment of airways hyperresponsiveness in vitro}

The stem bronchus was dissected from the left and right lower lung lobes of euthanized pigs on day 20 following completion of in vivo measurements. The parenchyma was removed, side branches were ligated and a $25 \mathrm{~mm}$-long segment was mounted in an organ bath, as previously described [7, 13]. These segments were classified as small/medium sized based on internal diameter (2-3 mm), location (spanning generations 9-14), and the presence of cartilage [14]. The segment adventitia was bathed in Kreb's solution and the lumen filled with Kreb's from a separate reservoir. Stopcocks at either end of the segment allowed the airway lumen to be sealed so that intralumenal pressure could be monitored using a calibrated pressure transducer [10]. Segments were checked for pressure leaks throughout each experiment.

Bronchi were electrically field stimulated (EFS, $60 \mathrm{~V}, 20 \mathrm{~Hz}$ and $3 \mathrm{~ms}$ pulses) using platinum ring electrodes and a Grass S44 stimulator (Grass Instruments, Quincy, MA, USA). EFS responses were used to assess the optimum passive pressure and stretch of segments $\left(5 \mathrm{cmH}_{2} \mathrm{O}\right.$ and $110 \%$ relaxed length, respectively, fig. 1) and to confirm that bronchial segments had recovered from the previous ACh concentration.

When a repeatable EFS response was obtained, a submaximal concentration of $\mathrm{ACh}, 1 \times 10^{-4} \mathrm{M}$, was added to the bath, followed by washout, to provide a stable contraction history. Cumulative CRCs to ACh $\left(1 \times 10^{-7}-1 \times 10^{-2} \mathrm{M}\right)$ were then obtained by adding $\mathrm{ACh}$ to the bath bathing the adventitial surface of the segment. After recovery, a noncumulative ACh
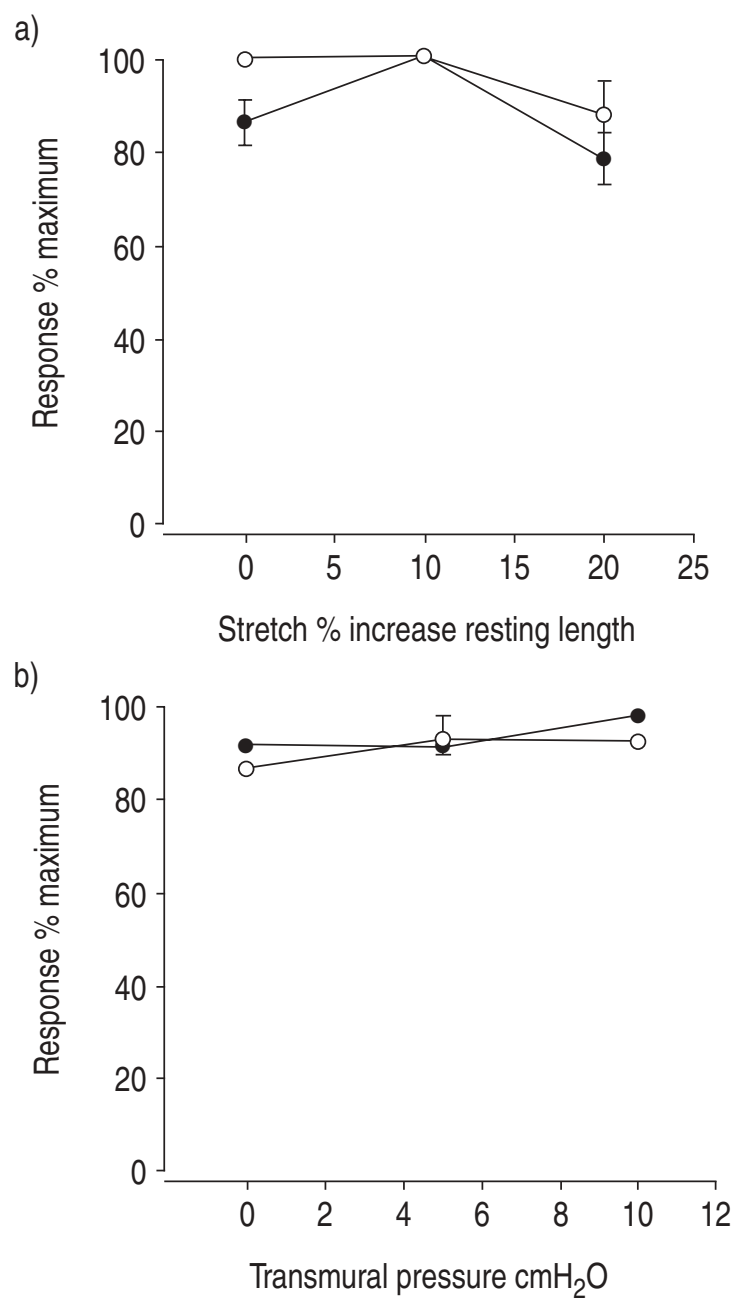

Fig. 1.-Effect of stretch (a) and passive transmural pressure (b) on responses to electrical field stimulation (EFS) in bronchial segments from test $(\bigcirc)$ and control $(\bigcirc)$ pigs. Responses were calculated as percentages of maximum EFS response in each bronchus and are expressed as a group mean \pm SEM. a) Responses varied with length in test bronchi, but not control (analysis of variance (ANOVA), $\mathrm{p}<0.02$ ). b) There were no significant differences at different transmural pressures or between control or test bronchi at individual pressures (ANOVA and two-tailed unpaired t-test). 
CRC $\left(1 \times 10^{-7}-1 \times 10^{-1} \mathrm{M}\right)$ was obtained by adding ACh to the fluid bathing the segment lumen $[10,13]$. Bronchial responsiveness in vitro was quantified as the maximum pressure developed in response to $\mathrm{ACh}$ $\left(E_{\max }\right)$ and the negative $\log$ of the ACh concentration that produced half the maximum pressure (pD2).

\section{Morphology}

Bronchi were fixed at an intralumenal pressure of $5 \mathrm{cmH}_{2} \mathrm{O}$ with $10 \%$ buffered formalin solution. Fixed tissues were paraffin embedded, $5 \mu \mathrm{m}$ sections were cut and stained with haematoxylin and eosin. ASM area, inner and outer wall area [15] and the lumen perimeter (Pi) were determined using image analysis software (Leading Edge Pty Ltd, Adelaide, South Australia). Measurements were averaged from five randomly-selected sections of each bronchus. Area was normalized [16] for differences In airway size by $\sqrt{\text { area/ }} \mathrm{Pi}$. The intra-observer coefficient of variation was $<1.3 \%$.

\section{Histology}

Representative sections of lower lung lobes were fixed in $10 \%$ buffered formalin. Fixed tissues were paraffin embedded, sectioned $(5 \mu \mathrm{m})$ and stained with haematoxylin and eosin. Tissue samples were assigned a code number and examined by the pathologist. Visual assessment of the overall architecture of the alveolar and bronchiolar tissue, degree of vascular disturbance (oedema, hyperaemia and haemorrhage) and the presence of inflammatory cells (neutrophils, eosinophils, macrophages and lymphocytes) were noted.

\section{Statistical analyses}

Cutaneous and lung responses to OA or saline, and the reactivity and sensitivity to ACh were compared within groups using paired t-tests and between groups using unpaired t-tests. In vivo and in vitro CRCs to ACh were compared between groups using nonlinear regression (F-test) Unpaired t-tests were used to compare morphological parameters.

Correlations were determined from data obtained in controls, test and nonresponder animals, using the method of least squares. A p-value $<0.05$ was regarded as significant. Data are shown throughout as mean \pm SEM, unless otherwise stated

\section{Results}

\section{Cutaneous responses}

Seven of eight test animals showed strong skin reactivity to intradermal OA on days 14 and 20. Positive responses occurred at a lower concentration on day 20 (geometric mean $0.019 \mathrm{mg} \cdot \mathrm{mL}^{-1}$, range $\left.0.001-0.01 \mathrm{mg} \cdot \mathrm{mL}^{-1}\right)$ than day $14\left(0.037 \mathrm{mg} \cdot \mathrm{mL}^{-1}\right.$, range $\left.0.01-0.1 \mathrm{mg} \cdot \mathrm{mL}^{-1}, \mathrm{p}<0.02\right)$. The remaining test animal had a weak response on both days $\left(1 \mathrm{mg} \cdot \mathrm{mL}^{-1}\right)$. Control animals showed no response to intradermal $\mathrm{OA}$.

\section{In vivo responses}

Naïve and sham-sensitized control animals showed no differences in lung function or responsiveness to ACh (table 1). The data was combined into one group $(n=8)$ for comparison with test animals.

Baseline $R \mathrm{~L}$ and $C \mathrm{~L}$ did not differ between test and controls on any study day Seven of the eight test pigs showed a strong increase in $R \mathrm{~L}(255 \pm 26 \%$, $\mathrm{p}<0.0001)$ and a corresponding decrease in $C \mathrm{~L}(90 \pm$ $3 \%, \mathrm{p}<0.0001)$ in response to OA aerosol on day 20 (fig. 2). Control animals showed no changes to saline aerosol ( $R \mathrm{~L}$ increased $11 \pm 4 \%, C \mathrm{~L}$ decreased $1 \pm 6 \%$ ). Peak responses occurred in all animals within $5 \mathrm{~min}$ of completing the aerosol.

Baseline $R \mathrm{~L}$ did not differ between preallergen/ saline exposure and the start of the CRC to ACh $1 \mathrm{hr}$ later (tests: $18.1 \pm 1.8 \mathrm{cmH}_{2} \mathrm{O} \cdot \mathrm{L}^{-1} \cdot \mathrm{s}$ and $17.8 \pm 1.5$; controls: $18.7 \pm 1.4$ and $18.3 \pm 1.7$, respectively). Test pigs showed a significant left shift in the CRC to ACh on day $20(\mathrm{p}<0.0001)$ compared to baseline values on day 14 (fig. 3). In contrast, control animals showed no change between day 14 and 20 (fig. 3).

Sensitivity to ACh doubled in test animals from day 14 to 20, but showed no change in controls. As illustrated in figure 3 , the concentration of ACh causing a $50 \%$ increase between baseline and maximal $R \mathrm{~L}$ (PC50) decreased in test pigs from a baseline of $9.9 \pm$ $1.5 \mathrm{mg} \cdot \mathrm{mL}^{-1}$ on day 14 to $5.1 \pm 0.9$ on day $20, \mathrm{p}=0.01$, while controls showed no change $\left(8.3 \pm 0.6 \mathrm{mg} \cdot \mathrm{mL}^{-1}\right.$ and $8.4 \pm 1.1$ ). PC50 was significantly different between the groups on day $20(\mathrm{p}<0.05)$, but not on day 14 .

Table 1. - Comparative data from naïve $(n=4)$ and sham-sensitized $(n=4)$ control animals

\begin{tabular}{lcc}
\hline & Naïve & Sham-sensitized \\
\hline Baseline $R \mathrm{~L} \mathrm{cmH}{ }_{2} \mathrm{O} \cdot \mathrm{L}^{-1} \cdot \mathrm{s}$ & & \\
$\quad$ Day 14 & $22.2 \pm 2.7$ & $17.9 \pm 2.0$ \\
$\quad$ Day 20 & $20.2 \pm 1.8$ & $16.8 \pm 2.3$ \\
Baseline $C \mathrm{~L} \mathrm{~mL} \cdot \mathrm{cmH}_{2} \mathrm{O}^{-1}$ & & \\
Day 14 & $12.9 \pm 2.2$ & $16.2 \pm 3.9$ \\
Day 20 & $14.4 \pm 1.4$ & $19.1 \pm 5.0$ \\
Max $R \mathrm{~L} \mathrm{cmH} \mathrm{C}_{2} \mathrm{O} \cdot \mathrm{L}^{-1} \cdot \mathrm{s}$ & & \\
Day 14 & $52 \pm 7$ & $65 \pm 13$ \\
Day 20 & $57 \pm 7$ & $57 \pm 9$ \\
Log PC50 & & \\
Day 14 & $3.26 \pm 0.04$ & $2.80 \pm 0.78$ \\
Day 20 & $3.22 \pm 0.33$ & $2.74 \pm 0.15$ \\
\hline
\end{tabular}

Data are presented as mean \pm SEM. $R \mathrm{~L}$ : pulmonary resistance; $C \mathrm{~L}$ : dynamic compliance; baseline $R \mathrm{~L}$ and $C \mathrm{~L}$ represents the baseline measurement prior to acetylcholine (ACh) exposure. Max $R \mathrm{~L}$ : the maximum $R \mathrm{~L}$ obtained from in vivo ACh concentration-response curve; PC50: ACh concentration required to increase $R \mathrm{~L} 50 \%$ between baseline and maximum, obtained from in vivo $\mathrm{ACh}$ concentration-response curve. No significant differences were found between the two group (unpaired t-test). 
a)

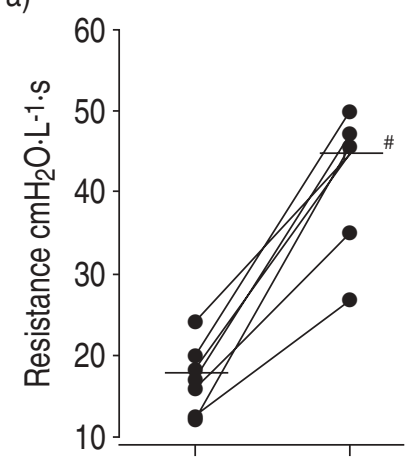

c)

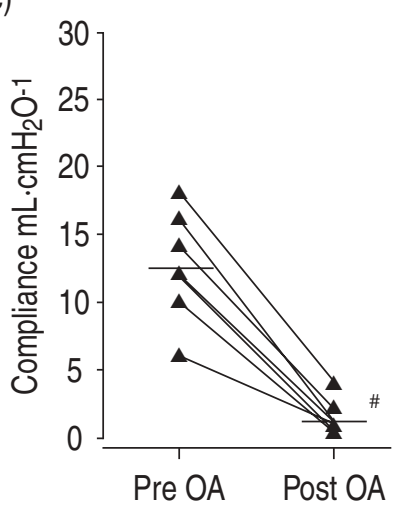

b)

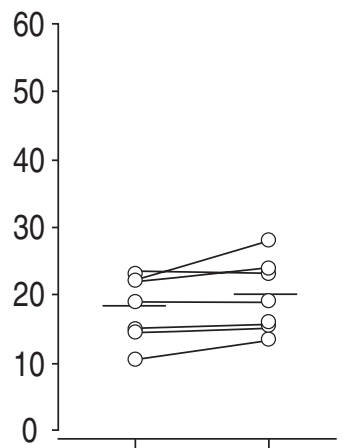

d)

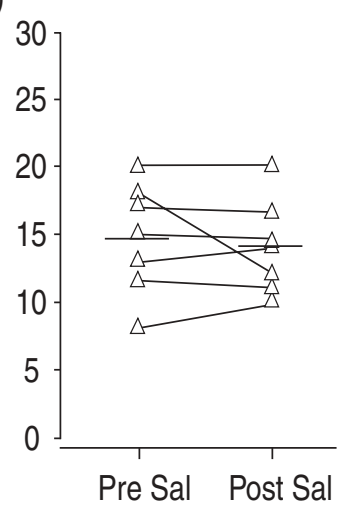

Fig. 2.-Paired measurements of resistance (a) test: $\mathbf{0}$; b) control: $\bigcirc)$ and compliance (c) test: $\boldsymbol{\Delta}$; control: $\triangle$ ) in individual pigs, pre and post in vivo aerosol challenge on day 20 . Test animals received an ovalbumin (OA) aerosol ( $\boldsymbol{O}$ and $\boldsymbol{\Delta}, \mathrm{n}=7$ ), control animals received a saline (Sal) aerosol $(\bigcirc$ and $\triangle, n=8)$. Mean responses are indicated with a horizontal bar. Test animals had a significant increase in both resistance and compliance following OA exposure $\left({ }^{\#}: \mathrm{p}<\right.$ $0.0001)$.

Mean maximal $R \mathrm{~L}$ increased from day 14 to 20 $(289 \pm 36 \%$ and $387 \pm 68 \%$ respectively, $\mathrm{p}<0.05)$ in test animals but did not change in controls $(295 \pm 49 \%$ on day 14 to $332 \pm 60 \%$ on day 20 ).

\section{Nonresponder}

One of the eight sensitized pigs showed minimal responses to aerosol OA on day 20 (fig. 4), no change in responsiveness following OA exposure (fig. 4), and had a very weak response to skin-prick testing $\left(1 \mathrm{mg} \cdot \mathrm{mL}^{-1}\right)$. The animal was classed as a nonresponder and excluded from the test group for analyses.

\section{Responsiveness of control and test bronchi in vitro}

Each pig yielded in vitro CRCs to adventitially applied ACh; however, only five animals per group produced maximum CRCs to lumenal ACh due to fatigue or development of a leak. The data from right and left bronchi were averaged, as no differences in responsiveness ( $\mathrm{pD}_{2}$ and $E_{\max }$ ) to $\mathrm{ACh}$ were found (table 2).

a)

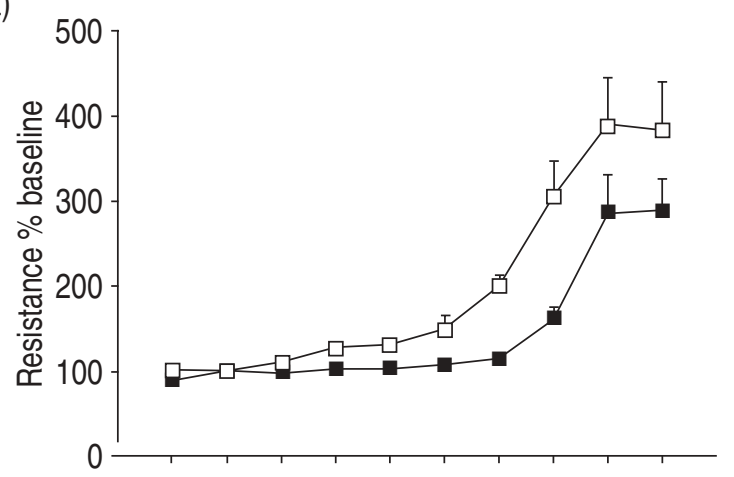

b)

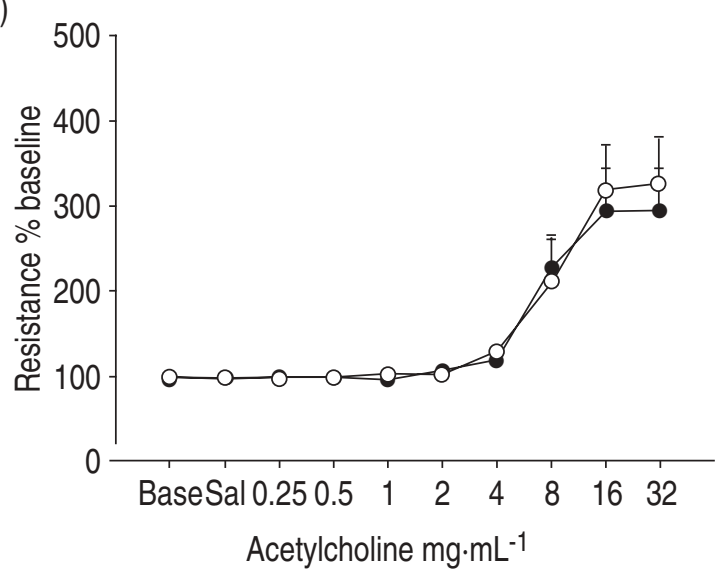

Fig. 3. - Mean \pm SEM resistance, expressed as a percentage of baseline (base), in response to inhaled acetylcholine (ACh) on days 14 and 20. a) Test animals $(n=7)$ showed a significant shift of the in vivo concentration response curve (CRC) on day $20(\square)$ compared to baseline measurements on day $14(\mathbf{\square}$; F-test, p<0.0001). The concentration of ACh causing a $50 \%$ increase between baseline and maximal pulmonary resistance $(R \mathrm{~L})$ was significantly decreased (paired t-test, $\mathrm{p}=0.01$ ) and maximal $R \mathrm{~L}$ significantly increased (paired t-test, $\mathrm{p}<0.05$ ) on day 20 versus day $14 . \mathrm{b}$ ) Control animals $(n=8)$ showed no change between day $14(\mathbf{O})$ and 20 (O). The CRC to ACh of test animals was different to that of controls on day 20 (F-test, $\mathrm{p}=0.005$ ), but not on day 14. Sal: saline.

Statistical analysis of the lumenal ACh CRC show a small, but significant, difference between test and control groups $(\mathrm{p}<0.03$, fig. 5); however, neither $\mathrm{pD} 2$ nor $E_{\max }$ differed between the groups (pD2: controls $2.84 \pm 0.13$ and tests $3.05 \pm 0.17 ;$ Emax: controls $60.1 \pm 4.1 \mathrm{cmH}_{2} \mathrm{O}$ and tests $61.1 \pm 4.9 \mathrm{cmH}_{2} \mathrm{O}$ ). In contrast to lumenal data, test bronchi showed a significant 2.5 -fold loss in contractile potency to adven titial ACh compared to controls ( $\mathrm{p}<0.0001$, fig. 5). $\mathrm{pD} 2$ was significantly reduced (control $4.58 \pm 0.10$, test $4.18 \pm 0.07, \mathrm{p}<0.01)$, although $E \max$ was not different between the two groups (control $82.1 \pm 3.4 \mathrm{cmH}_{2} \mathrm{O}$, test $75.6 \pm 7.5 \mathrm{cmH}_{2} \mathrm{O}$, fig. 5).

\section{Morphometry}

ASM area was increased in test pigs $(0.064 \pm$ $0.004 \mathrm{~mm}, \mathrm{p}<0.05)$ compared to controls $(0.054 \pm$ 0.001 ) (table 3). There were no differences in 
a)

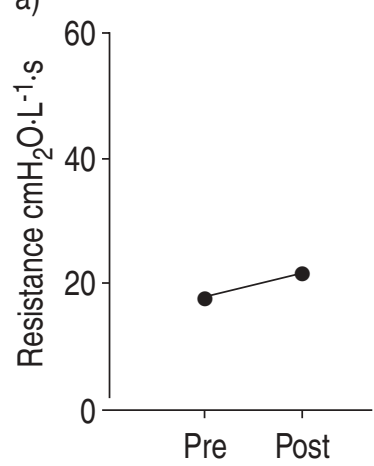

c)

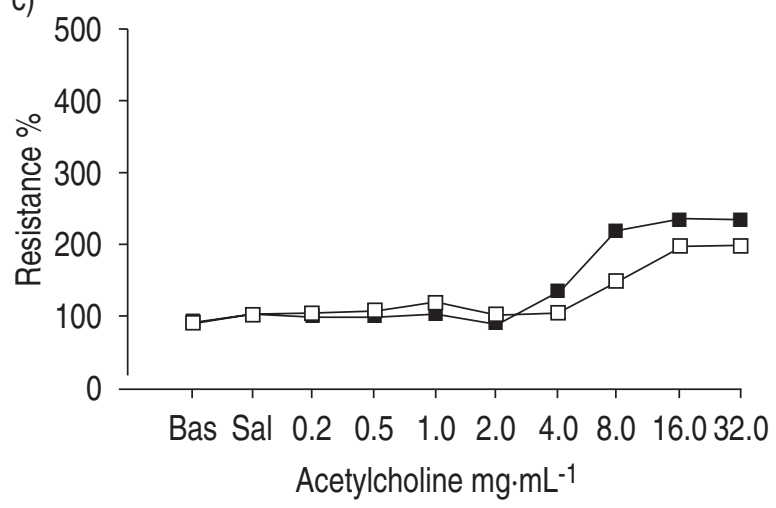

Fig. 4.-Resistance (a) and compliance (b) before (pre) and after (post) exposure to ovalbumin aerosol (OA) on day 20 in a "nonresponder" test animal. c) Resistance, expressed as a percentage of baseline (base), was in response to inhaled acetylcholine (ACh) on days $14(\mathbf{\square})$ and $20(\square)$. This animal showed no airway response to OA and did not develop hyperresponsiveness to ACh by day 20 . Sal: saline.

inner, outer or total wall area between the two groups (table 3 ). The epithelium was $>85 \%$ intact in both control and test bronchi, and of normal appearance.

Table 2. - Comparison of physiological data obtained from paired left and right lower lobe bronchial segments from control and test pigs $(n=3-5)$

\begin{tabular}{lccc}
\hline & Bronchi & Left & Right \\
\hline pD2 & & & \\
Lumen & Control & $2.76 \pm 0.21$ & $2.73 \pm 0.14$ \\
& Test & $2.88 \pm 0.51$ & $3.05 \pm 0.36$ \\
Adventitia & Control & $4.75 \pm 0.12$ & $4.54 \pm 0.19$ \\
& Test & $4.24 \pm 0.13$ & $4.20 \pm 0.10$ \\
Emax $\mathrm{cmH}_{2} \mathrm{O}$ & & & \\
Lumen & Control & $63.9 \pm 3.6$ & $67.2 \pm 2.8$ \\
& Test & $53.9 \pm 3.4$ & $56.0 \pm 3.1$ \\
Adventitia & Control & $79.0 \pm 4.9$ & $74.7 \pm 8.8$ \\
& Test & $78.9 \pm 15.7$ & $66.0 \pm 11.4$ \\
\hline
\end{tabular}

Data are presented as mean \pm SEM. Emax: maximum response; pD2: the -log Concentration of Acetylcholine (ACh) producing half $E \max$. Emax and pD2 were recorded in response to ACh administered either to the airway lumen or adventitia. There were no significant differences between left or right lobe bronchi.

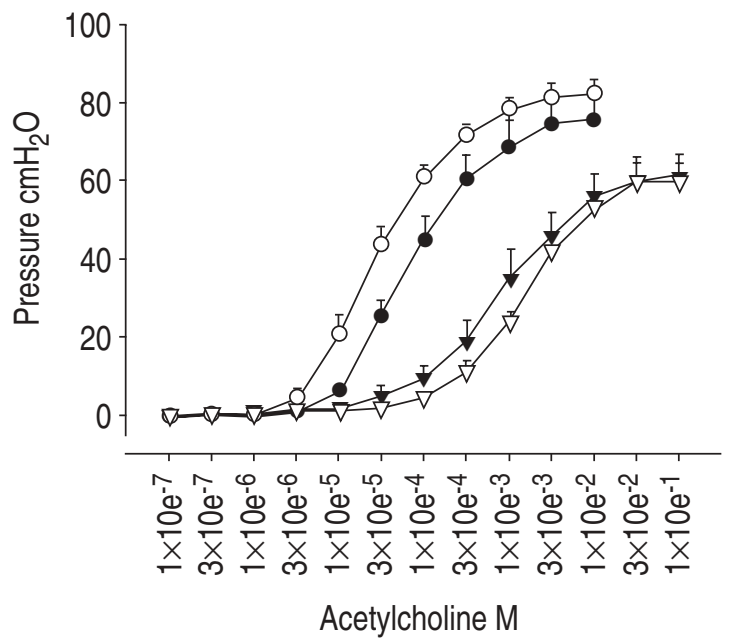

Fig. 5. - Increases in pressure $\left(\mathrm{cmH}_{2} \mathrm{O}\right)$ in response to acetylcholine $(\mathrm{ACh})$ in bronchial segments from test (adventitia: 0 ; lumen: $\boldsymbol{\nabla} ; \mathrm{n}=7$ ) and control (adventitia: $\bigcirc$; lumen: $\nabla ; \mathrm{n}=8$ ) pigs. Mean \pm SEM control and test concentration-response curves were significantly different for both adventitial $(\mathrm{p}<0.0001$, F-test $)$ and lumenal $(\mathrm{p}<0.03$, F-test) administration of $\mathrm{ACh}$. The $-\mathrm{log}$ concentration of $\mathrm{ACh}$ producing half the maximum pressure developed in response to $\mathrm{ACh}\left(E_{\max }\right)$ was significantly reduced in test animals $(\mathrm{p}<0.01)$ compared to controls in response to adventitial ACh only.

\section{Responsiveness in vivo versus in vitro}

Responsiveness of isolated bronchial segments to lumenal ACh was compared with in vivo responsiveness to aerosol ACh in control, test and nonresponder pigs. Reactivity to ACh in vivo (Rmax) showed a weak positive correlation with reactivity in vitro (Emax) $(\mathrm{r}=0.599, \mathrm{p}=0.05)$. However, there was no correlation between sensitivity ( $\log \mathrm{PC} 50)$ values in vitro and in vivo $(\mathrm{r}=0.441, \mathrm{p}=0.175)$. Adventitial responses to $\mathrm{ACh}$ were also compared with in vivo responses. No correlation was found in reactivity ( $R \max$ versus $E \max , \mathrm{r}=0.079$, $\mathrm{p}=0.77)$ or sensitivity $(\log \mathrm{PC} 50, \mathrm{r}=0.381, \mathrm{p}=0.146)$.

\section{Histology}

Lymphocytes, neutrophils and eosinophils were evident in the parenchyma of test pigs. There was frequent, mild granulocytic cuffing around small bronchioles and an increase in cellularity within interstitial areas. Control animals showed occasional areas of increased cellularity, primarily due to atelectasis of

Table 3.-Morphometric analysis of the airway wall in bronchi from test $(n=4)$ and control $(n=4)$ pigs

\begin{tabular}{lccc}
\hline & $\begin{array}{c}\text { Inner } \\
\text { airway wall }\end{array}$ & $\begin{array}{c}\text { Outer } \\
\text { airway wall }\end{array}$ & $\begin{array}{c}\text { Smooth } \\
\text { muscle }\end{array}$ \\
\hline Test & $1.046 \pm 0.211$ & $4.144 \pm 0.880$ & $0.064 \pm 0.004^{*}$ \\
Control & $1.206 \pm 0.344$ & $3.817 \pm 0.682$ & $0.054 \pm 0.001$ \\
\hline
\end{tabular}

Data were standardized for airway size and are presented as mean \pm SEM $\mathrm{mm} / \mathrm{mm}$. Measurements were made of inner airway wall, other airway wall, and airway smooth muscle areas. *: $\mathrm{p}<0.05$, unpaired $\mathrm{t}$-test for test versus control. 
the parenchyma. Larger airways were normal in appearance in both test and control pigs. No differences were observed in overall architecture of the tissue, or the degree of vascular disturbance between the two groups.

\section{Discussion}

This study is the first to report functional properties of whole bronchi in a model of AHR. The model incorporates the primary characteristics of asthma, namely airway narrowing, AHR and inflammation. A unique feature of this model is that the size and ready availability of the animal allows the airway physiology of small to medium size bronchi to be studied in vitro after demonstration of AHR in vivo. This allows comparisons to be drawn between physiological properties of the airway wall in vitro and lung responsiveness. In addition, the use of bronchial segments to assess airway function in vitro allows responsiveness to be determined separately for ASM (via adventitial application of $\mathrm{ACh}$ ) and for the airway wall (via the lumen). The results from the present study imply that repeated allergen challenge in sensitized pigs produces complex changes affecting several components of the bronchial wall. Evidence suggests that ASM is less responsive in allergen exposed bronchi than controls, indicating that AHR in vivo may be associated with other factors which regulate ASM contraction, such as airway structure or external loads from the parenchyma.

Bronchi from sensitized pigs had increased ASM, which is consistent with airway remodelling as seen in asthmatics [16]. However, when assessed in vitro bronchi from sensitized pigs were less responsive to adventitial ACh than controls. Responsiveness could be influenced by inflammatory stimulation and also by the presence of smooth muscle cells with different contractile or secretory phenotypes [17]. In some animal models, tracheal smooth muscle contraction is increased [1-3]. There are fewer studies in bronchi, but one human study showed decreased smooth muscle force in bronchi obtained post mortem [5]. The reduced bronchial response to adventitial ACh in the present study suggests that ASM force and sensitivity is decreased despite the presence of more ASM. At present, the authors have no information on contractions in more peripheral airways, which might show different levels of responsiveness. In contrast to the adventitial route, there was a modest rightward shift in the lumenal CRC of sensitized bronchi, the route considered to be more physiological. The small increase in lumenal sensitivity suggests the presence of some mechanism(s) within the airway wall which act to increase activation of ASM. Of particular importance is the lining epithelium, which if damaged leads to major increases in lumenal responsiveness due to increased drug penetration to the underlying smooth muscle [13]. Although no gross alterations to epithelial morphology were observed in the test bronchi of this study, more subtle changes in epithelial permeability may have been present.

The prevalence of early airway responses to inhaled allergen using this porcine model was $87 \%$, which compares favourably with other allergic animal models [18]. One sensitized pig failed to respond to OA aerosol and showed a poor cutaneous response compared to the other seven test animals. This biological variation is typical of species that are not highly inbred, hence some research groups use screening tests, such as cutaneous responses, to preselect the animals they study [11, 18-20]. The antigen-sensitized animals developed a typical wheal and flare response, suggesting a production of antigen-specific immunoglobulin-E (IgE) antibodies [12]; whereas, neither naïve nor sham-sensitized control pigs responded to cutaneous antigen. A more sensitive index of sensitization would be advantageous. To date, it is not possible to measure porcine IgE concentrations directly, as there are no commercially-available antiporcine IgE monoclonal antibodies. However, significant advances have recently been made with the isolation of the pig IgE epsilon chain [21].

All control animals were exposed to an aerosol of saline, rather than $\mathrm{OA}$ in saline diluent, as repeated OA aerosol exposure may be sufficient to sensitize the animal in the absence of an initial antigen injection [22]. Sham-sensitized pigs showed the same responses as naïve pigs (table 1). A third control group of OA-sensitized and saline-challenged pigs had been previously assessed in the present authors' laboratory with similar results (unpublished data).

Multiple allergen exposure has been used in several animal models [23-25] to induce some of the functional and struclural changes seen in asthma. In this study, three aerosol exposures to $\mathrm{OA}$ resulted in a mild inflammation in test animals particularly in the small airways. There was also an increase in ASM area, but no other changes in overall architecture of the tissue or degree of vascular disturbance distinguished test animals from controls.

An aim of the present study was to determine whether differences in the responsiveness of lungs in vivo could be accounted for by properties of the isolated airway wall. Data from control, test and nonresponder pigs were combined providing a broad range of responses. The present study demonstrates a relationship between maximal responses to lumenal challenge in vivo and in vitro. Previous studies using rings or strips of smooth muscle [8] have failed to show such an association, possibly because the dissection procedure may compromise the epithelium and other structural features that contribute to responsiveness in vivo. More recently, MASAKI et al. [26] showed a positive correlation between the effect of lumenally-applied $\mathrm{ACh}$ on tracheal narrowing in vitro and insufflation pressure in vivo in an OA-sensitized cohort of guinea pigs. In contrast, a study by WoIsIN et al. [27] found no correlation between in vivo and in vitro responsiveness in control and sensitized rabbits; however, the sensitized cohort failed to show hyperresponsiveness when compared to the controls. The present study extends these findings as it includes a cohort of normal pigs together with sensitized animals exhibiting clear AHR.

The present results suggest that reactivity in vivo may be related to reactivity in the individual 
bronchus, as determined in vitro. There was no such relationship between sensitivities in vivo and in vitro. These findings are consistent with sensitivity arising as a result of more than one mechanism. Extrinsic airway mechanisms, as well as local airway alterations, could contribute to responsiveness as suggested by others [6]. The present authors have previously shown that bronchi from test pigs are less compliant than controls [7], which is consistent with structural remodelling. In the present study, test animals showed airway wall remodelling in the form of increased airway smooth muscle area. This could lead to stiffer airways, which could be less prone to forces of interdependence in the lungs. Any reduction in the afterload on airway smooth muscle contraction, arising from forces of interdependence, might favour airway narrowing in vivo, but would not be apparent in the individual airway in vitro. Subsequent studies using this model may uncover, at the cellular level, mechanisms producing changes to airway function in the bronchial wall.

\section{References}

1. Antonissen LA, Mitchell RW, Kroeger EA, Kepron W, Tse KS, Stephens NI. Mechanical alteration of airway smooth muscle in canine asthmatic model. J Appl Physiol 1979; 46: 681-687.

2. Garssen J, Nijkamp FP, van der Vliet H, van Loveren HT. T-cell mediated induction of airway hyperreactivity in mice. Am Rev Respir Dis 1991; 144: 931-938.

3. Ishida K, Kelly LJ, Thomson RJ, Beattie LL, Schellenberg RR. Repeated antigen challenge induces airway hyperresponsiveness with tissue eosinophilia in guinea pigs. J Appl Physiol 1989; 67: 1133-1139.

4. Schellenberg RR, Foster A. In vitro responses of human asthmatic airway and pulmonary vascular smooth muscle. Int Arch Allergy Appl Immunol 1984; 75: 237-241.

5. Goldie R, Spina D, Henry P, Lulich K, Paterson J. In vitro responsiveness of human asthmatic bronchus to carbachol, histamine, beta-adrenoceptor agonists and theophylline. Br J Clin Pharmacol 1986; 22: 669676.

6. Macklem PT. Mechanical factors determining maximum bronchoconstriction. Eur Respir $J$ 1989; 2: Suppl. 6, 516s-519s

7. Mitchell HW, Turner DJ, Gray PR, McFawn PK. Compliance and stability of the bronchial wall in a model of allergen-induced lung inflammation. $J$ Appl Physiol 1999; 186: 932-937.

8. Black JL. Airways smooth muscle in asthma. In: Barnes PJ, Grunstein MM, Leff AR, Woolcock AJ, eds. Asthma. Philadelphia, New York, LippincottRaven, 1997; pp. 809-822.

9. Mitchell HW, Sparrow MP. Increased responsiveness to cholinergic stimulation of small compared to large diameter cartilaginous bronchi. Eur Respir J 1994; 17: 298-305.

10. Gray PR, Mitchell HW. Effect of diameter on force generation and responsiveness of bronchial segments and rings. Eur Respir J 1996; 19: 500-505.
11. Alving K, Matran R, Lacroix JS, Lundberg JM. Capsaicin and histamine antagonist-sensitive mechanisms in the immediate allergic reaction of pig airways. Acta Physiol Scand 1990; 138: 49-60.

12. Sears MR. Risk factors: immunoglobulin $E$ and atopy. In: Barnes PJ, Grunstein MM, Leff AR, Woolcock AJ, eds. Asthma. Philadelphia, New York, LippincottRaven, 1997; pp. 71-82.

13. Sparrow MP, Mitchell HW. Modulation by the epithelium of the extent of bronchial narrowing produced by substances perfused through the lumen. $\mathrm{Br}$ J Pharmacol 1991; 103: 1160-1164.

14. McFawn PK, Mitchell HW. Bronchial compliance and wall structure during development of the immature human and pig lung. Eur Respir J 1997; 10: 27-34.

15. Bai A, Eidelman DH, Hogg JC, et al. Proposed nomenclature for quantifying subdivisions of the bronchial wall. J Appl Physiol 1994; 77: 1011-1014.

16. Carroil N, Elliot J, Morton A, James A. The structure of large and small airways in nonfatal and fatal asthma. Am Rev Respir Dis 1993; 147: 405-410.

17. Stephens NL, Li W, Wang Y, Ma X. The contractile apparatus of airway smooth muscle. Am J Respir Crit Care Med 1998; 15: S80-S94.

18. Turner DJ, Martin JG. Animal models. In: Barnes PJ, Grunstein MM, Leff AR, Woolcock AJ, eds. Asthma. Philadelphia, New York, Lippincott-Raven, 1997; pp. 261-274.

19. Fornhem C, Lundberg JM, Alving K. Allergeninduced late-phase airways obstruction in the pig: the role of endogenous cortisol. Eur Respir J 1995; 8: 928-937.

20. Fornhem C, Kumlin M, Lundberg JM, Alving K. Allergen-induced late-phase airways obstruction in the pig: mediator release and eosinophil recruitment. Eur Respir J 1995; 8: 1100-1109.

21. Vernersson M, Gunnar P, Kristersson T, Alving K, Hellman L. Cloning, structural analysis, and expression of the pig $\operatorname{IgE} \varepsilon$ chain. Immunogenetics 1997; 46: 461-468.

22. Holt PG, Batty JE, Turner KJ. Inhibition of specific $\mathrm{IgE}$ responses in mice by pre-exposure to inhaled antigen. Immunology 1981; 42: 409-417.

23. Haczku A, Moqbel R, Elwood W, et al. Effects of prolonged repeated exposure to ovalbumin in sensitized brown Norway rats. Am J Respir Crit Care Med 1994; 150: 23-27.

24. Sapienza S, Du T, Eidelman DH, Wang NS, Martin JG. Structural changes in the airways of sensitized brown Norway rats after antigen challenge. Am Rev Respir Dis 1991; 144: 423-427.

25. Padrid P, Snook S, Finucane T, et al. Persistant airway hyperresponsiveness and histologic alterations after chronic antigen challenge in cats. Am J Respir Crit Care Med 1995; 151: 184-193.

26. Masaki Y, Munakata M, Amishima M, Homma Y, Kawakami Y. In vivo, in vitro correlation of acetylcholine airway responsiveness in sensitized guinea pigs. Am J Respir Crit Care Med 1994; 149: 1494 1498.

27. Woisin FE, Herd CM, Douglas GJ, et al. Relationship of airway responsiveness with airway morphometry in normal and immunised rabbits. Pulm Pharmacol Ther 2001; 14: 75-83. 